\title{
Antifungal activity of propolis extract against yeasts isolated from onychomycosis lesions
}

\section{Ana Carla Pozzi O liveira, Cristiane Suemi Shinobu, Renata Longhini*, Selma Lucy Franco*, Terezinha Inez Estivalet Svidzinski/ ${ }^{+}$} Laboratório de Micologia, Departamento de Análises Clínicas *Departamento de Farmácia e Farmacologia, Centro de Ciências da
Saúde, Universidade Estadual de Maringá, Av. Colombo 5790, Bloco J90, sala 11, 87020-900 Maringá, PR, Brasil

The aim of this study was to determine the in vitro activity of propolis extract against 67 yeasts isolated from onychomycosis in patients attending at the Teaching and Research Laboratory of Clinical Analysis of the State University of Maringá. The method used was an adaptation made from the protocol approved by the National Committee for Clinical Laboratory Standards. The yeasts tested were: Candida parapsilosis 35\%, C. tropicalis 23\%, C. albicans $13 \%$, and other species $29 \%$. The propolis extract showed excellent performance regarding its antifungal activity: the concentration capable of inhibiting the all of the yeasts was $5 \times 10^{-2} \mathrm{mg} / \mathrm{ml}$ of flavonoids and $2 \times$ $10^{-2} \mathrm{mg} / \mathrm{ml}$ of flavonoids stimulated their cellular death. Trichosporon $\mathrm{sp}$. were the most sensitive species, showing $M I C_{50}$ and $M I C_{90}$ of $1.25 \times 10^{-2} \mathrm{mg} / \mathrm{ml}$ of flavonoids, and C. tropicalis was the most resistant, with $\mathrm{CFM}_{50}$ of $5 \times$ $10^{-2} \mathrm{mg} / \mathrm{ml}$ of flavonoids and $M F C_{90}$ of $10 \times 10^{-2} \mathrm{mg} / \mathrm{ml}$. In view of the fact that propolis is a natural, low cost, nontoxic product with proven antifungal activity, it should be considered as another option in the onychomycosis treatment.

Key words: propolis - flavonoids - antifungal activity - yeasts - onychomycosis

Onychomycosis is a common onychopathy due to invasion of the nail by fungi that represents up to $50 \%$ of all nail problems. Onychomycosis is not important in terms of morbidity and mortality, but can seriously affect the quality of patient's life (Fouilloux 2003).

Different clinical patterns of infection can be observed, depending on the manner and extent by which fungi invade the nail, and also on the kind of fungi (Gupta et al. 2004b). Onychomycosis by yeasts can manifest itself in several clinical presentations: chronic paronychia with secondary nail dystrophy, distal nail infection, chronic mucocutaneous candidiasis, and secondary candidiasis (Roberts et al. 2003).

Onychomycosis is predominantly caused by anthropophilic dermatophyte fungi, but in recent years yeasts and non-dermatophyte molds have also been regarded as frequent agents of onychomycosis (Araujo et al. 2003, Gupta et al. 2004b). In the past, dermatophytes were responsible by $90 \%$ of cases, but nowadays the prevalence of other agents has increased and laboratory diagnosis has become necessary (Summerbell et al. 2005).

Differences in the incidence of onychomycosis have been reported not only among different countries, but also for different regions of the same country. Epidemiological studies concerning onychomycosis have been performed in many countries around the world: Lybia (Ellabib et al. 2002), Slovakia (Dorko et al. 2002), India

+Corresponding author: tiesvidzinski@uem.br Received 17 January 2006

Accepted 15 May 2006
(Garg et al. 2004), Argentina (Mujica et al. 2004), Taiwan (Chi et al. 2005), Italy (Romano et al. 2005), Germany (Effendy et al. 2005), Turkey (Ilkit 2005), and Greece (Ioannidou et al. 2006). In all cases, infection of the nail by yeasts, mainly Candida sp., has been prominent. In Ceará, Brazil, this tendency also was observed (Brilhante et al. 2005).

Despite the great progresses observed in the last decades and the development of new antifungals, the onychomycosis treatment still represents a significant problem. It depends on several variables, including the type of onychomycosis and the causative organism. Prior to treatment, an accurate diagnosis can provide guidance about the choice of antifungal agent, especially as the causative organism may vary in its response to the antifungal therapies available (Gupta et al. 2004b). Current therapeutic approaches include topical therapy, oral therapy with terbinafine, itraconazole, fluconazole, and ketoconazole (Roberts et al. 2003) or a combination of two or more of these treatment modalities (Gupta et al. 2004a, Baran \& Kaoukhov 2005).

It seems that systemic treatment is more effective, especially for chronic infections, but due to the toxicity of the antifungal when administered orally, in some cases, topical treatment may be recommend as first choice. Topical treatment is indicated for localized and non-extensive infections. However, if it fails, or if more than $50 \%$ of the nail, including the matrix area, is infected, systemic drugs should be prescribed. According Lecha et al. (2005), in these cases, oral monotherapy or a combination therapy is indicated.

However, various reasons can make the therapeutic choice, and its success, limited: indiscriminate use of specific drugs prescribed without previous determination by specific laboratory exams, use of drugs with an inadequate 
spectrum activity, low tolerance rates, interactions with other drugs, and inadequate pharmacokinetic profiles (Baran et al. 2005). Moreover, the high cost of treatment presents a serious problem for the Public Health System.

Propolis (bee glue) stands out when searching for a potentially efficient and low cost treatment. It is a resin, originating from trees, which is collected by bees and is considered a 'natural antibiotic' without serious side effects, in comparison to synthetic treatments, and presents several pharmacological properties (De Castro 2001). Among the substances present in propolis, the flavonoids are present in great amount, which are identified as being responsible for its anti-inflammatory, antimicrobial, and in particular its antifungal actions (Somnez et al. 2005, Cusnhie \& Lamb 2005).

Thus, the aim of present study was to evaluate the in vitro susceptibility of the propolis extract against yeasts isolated from onychomycosis, in order to determine the smallest concentration of extract capable of inhibiting or preventing the growth of pathogenic yeasts, to determine the susceptibility profile, and to evaluate the possibility of using it as topical treatment for onychomycosis infections.

\section{MATERIALS AND METHODS}

Materials - The propolis samples were collected from hives of Apis mellifera L bees at the Iguatemi Experimental Farm, which belongs to the State University of Maringá (FEI-UEM). The apiary was located inside a eucalyptus reserve surrounded by native forest. Propolis collection was carried out both inside and outside the hive, with the surfaces being scraped smoothly with a wooden chisel. The samples were combined into a single batch, packed in a sealed plastic bag, and stored at under $-20^{\circ} \mathrm{C}$.

Preparation of the extract - The propolis extract was prepared in a $30 \%(\mathrm{w} / \mathrm{w})$ concentration with $96^{\circ} \mathrm{GL}$ alcohol as the extractor liquid. The extract was placed in an amber flask, well sealed, and stored at room temperature.

Quality control of the extract - The flavone content (Franco \& Bueno 1999), the $\mathrm{pH}$ and density (Farmacopeia Brasileira 1998), the dry residue and the extracted content were determined according Mello et al. (1996).

Microorganisms - Samples of onychomycosis from fingernails and toenails of patients who had been attending the Laboratory of Teaching and Research in Clinical Analyses, USM, were used. The samples were cultivated in five tubes containing Sabouraud Dextrose Agar-SDA (Merck, Germany) with chloramphenicol (0.02\%), which were incubated at $25^{\circ} \mathrm{C}$. A pool of colonies from repetitive cultures was inoculated with a bacteriological loop onto the surface of a differential selective medium, CHROMagar Candida (CHROMagar ${ }^{\mathrm{TM}}$ Microbiology, Paris, France) in Petri dishes. These dishes were incubated at $25^{\circ} \mathrm{C}$ for 48 $\mathrm{h}$. Yeasts were identified by germ tube production, micromorphology and clamydospore production on Tween 80corneal agar, and assimilation and fermentation tests.

Sixty-seven yeasts were used for this study. After identification, the yeasts were maintained at $4^{\circ} \mathrm{C}$ in sterile distilled water.
Susceptibility test - Yeasts were reactivated in SDA and an inoculum was prepared in sterile saline. The cellular density was adjusted by a spectrophotometer, Bausch \& Lomb, at $530 \mathrm{~nm}$, with $90 \pm 2 \%$ transmittance. This turbidity resulted in a concentration of 1 to $5 \times 10^{6} \mathrm{cfu} / \mathrm{ml}$. New dilutions in Yeast Nitrogen Base Glucose (YNBG) broth were prepared in order to obtain the final desired inoculum between 0.5 and $2.5 \times 10^{3} \mathrm{cfu} / \mathrm{ml}$.

The minimum inhibitory concentration (MIC) was determined by the broth microdilution method, basically following the norms of the National Committee For Clinical Laboratory Standards (NCCLS 1997), published in the M27A Document, but with some adaptations for natural products.

The test was performed in sterilized plastic microplates (Nunclon, Delta, Nunc A/S, Roskilde, Denmark) containing 96 wells organized in eight rows, identified from A to $\mathrm{H}$, with each row containing 12 wells, numbered from one to 12. Each row $(\mathrm{A}-\mathrm{H})$ corresponded to one yeast strain ( $100 \mu \mathrm{l}$ of the calibrated inoculum), and the columns received the seriately diluted propolis extract, with each column being twice as diluted as the previous one in YNBG broth until a dilution of 1/128 was obtained, which corresponded to a final concentration of $0.63 \times 10^{-2} \mathrm{mg} / \mathrm{ml}$ of flavonoids.

In each plate, the following controls were included: negative, positive, diluent (alcohol), and C. parapsilosis yeast (ATCC 22019). The plates were incubated for $72 \mathrm{~h}$ at $35^{\circ} \mathrm{C}$ with daily monitoring. The colonies were analyzed by visual comparison through reflection on mirror.

The MIC was considered as the smallest propolis concentration capable of inhibiting $80 \%$ of the growth of each yeast, having as a reference its respective positive control. For determination of the minimum fungicidal concentration (MFC), aliquots of the MIC wells were transferred to a culture media without the drug. The MFC was considered as the smallest dilution that prevented the growth of yeasts.

Analysis of results - The results of the MICs and MFCs obtained were analyzed by the following parameters: (a) the range of values representing the lowest and highest limits of the MICs and MFCs of propolis extract, for the different species of yeasts tested, (b) $\mathrm{MIC}_{50}$ and $\mathrm{MIC}_{90}$ defined as the minimum inhibitory concentration of the drug capable of inhibiting the growth of 50\% and $90 \%$ of the samples tested, respectively, and (c) $\mathrm{MFC}_{50}$ and $\mathrm{MFC}_{90}$ defined as the minimum fungicidal concentration of the drug capable of preventing growth of 50 and $90 \%$ of the samples tested, respectively.

\section{RESULTS}

The 67 samples of yeasts isolated and identified from samples of onychomycosis comprised the following species: eight C. albicans, 23 C. parapsilosis, 15 C. tropicalis, two $C$. kefyr, two $C$. guilliermondii, five $C$. lusitanea, two C. glabrata, one C. stellatoidea, five Trichosporon sp. including (T. asahii, T. ovoides and T. cutaneum), one Geotrichum candidum and three Saccharomyces cerevisiae (Fig. 1).

Before the susceptibility tests, the propolis extract $(n=5)$ was submitted to quality control, following the 


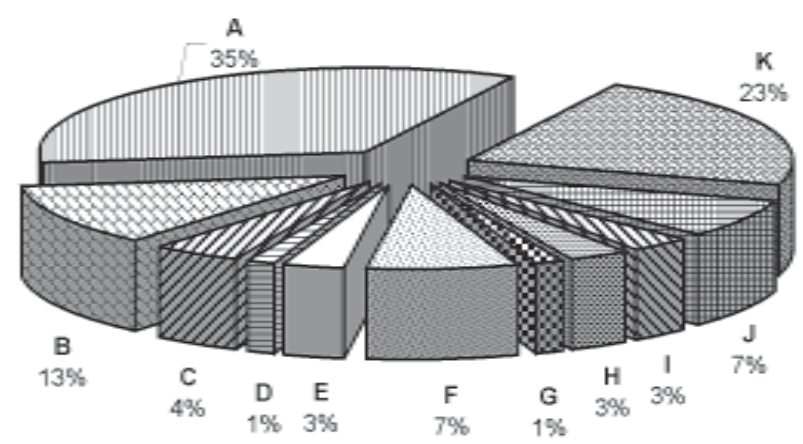

Fig. 1: distribution of species of yeasts isolated from onychomycosis. A: Candida parapsilosis; B: C. albicans; C: Saccharomyces cerevisiae; D: Geotrichum candidum; E: C. glabrata; F: Trichosporon spp.; G: C. stellatoidea; H: C. guiliermondii; I: C. kefyr; J: C. lusitanea; K: C. tropicalis.

techniques approved in official codes, and the respective results are shown in Table I.

Using the 67 yeasts isolates, MIC and MFC results for the propolis extract, determined by total flavone content (one of the groups of substances present in propolis that has antifungal activity), were obtained.

Regarding to the MICs, 33 yeasts were sensitive to the $1.25 \times 10^{-2} \mathrm{mg} / \mathrm{ml}$ concentration of total flavonoids, 59 to the $2.5 \times 10^{-2} \mathrm{mg} / \mathrm{ml}$ concentration and all the yeasts to the $5 \times 10^{-2} \mathrm{mg} / \mathrm{ml}$ concentration of total flavonoids (Fig. 2).

The concentration of $2.5 \times 10^{-2} \mathrm{mg} / \mathrm{ml}$ of flavonoids was fungicidal for 35 yeasts, $5 \times 10^{-2} \mathrm{mg} / \mathrm{ml}$ prevented the growth of 61 yeasts and $20 \times 10^{-2} \mathrm{mg} / \mathrm{ml}$ of flavonoids was sufficient to prevent the growth of all the yeasts tested (Fig. 3).

The degree of susceptibility of the yeasts to propolis was different among the species. Trichosporon sp. were the most sensitive, for the $\mathrm{MIC}_{50}$ the most resistant species were $C$. albicans and $C$. tropicalis, and for the $\mathrm{MIC}_{90}$ the most resistant species were $C$. tropicalis and $C$. lusitanea (Table II).

In relation to fungicidal activity, the following variations were also observed: $C$. tropicalis required the largest concentration of propolis to prevent its growth, while in Trichosporon sp. cellular death was observed with a small concentration (Table III).

The extractor liquid, $96^{\circ} \mathrm{GL}$ alcohol, did not interfere in the in vitro performance of the propolis extract against the yeasts isolated from patients and the control yeast.

\section{TABLE I}

Quality control data for the propolis extract

\begin{tabular}{lccc}
\hline Parameters & Average value & S.D. & CV \% \\
\hline Flavonoid content $(\%)$ & 0.92 & 0.0132 & 1.44 \\
Relative density & 0.8608 & 0.0035 & 0.40 \\
Dry residue (\%) & 15.00 & 0.6976 & 4.65 \\
pH value & 5.62 & 0.0150 & 0.27
\end{tabular}

The parameters were obtained according to the techniques approved in official codes; number of extracts: 5; S.D.: standard deviation; CV: coefficient of variation (\%).

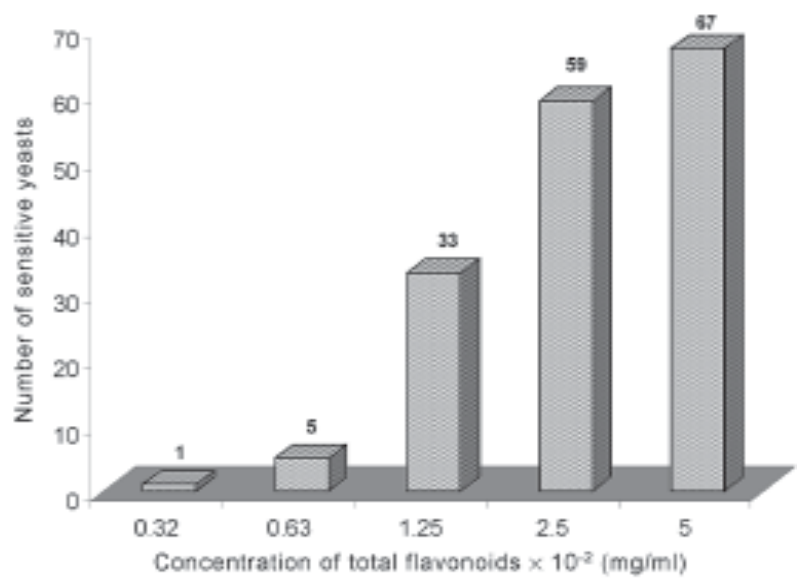

Fig. 2: cumulative numbers of the susceptibility of 67 onychomycosis-causing yeasts to propolis extract (by flavonoids content, $\mathrm{mg} / \mathrm{ml}$ ), expressed for each observed minimum inhibitory concentration.

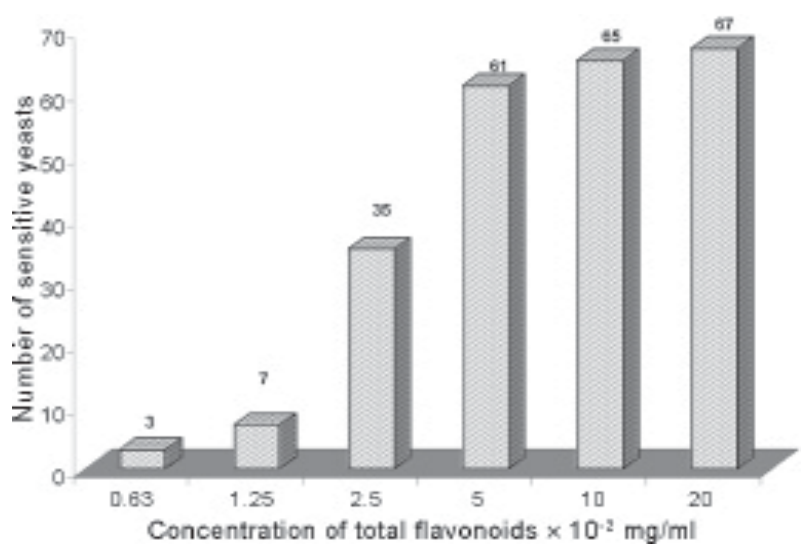

Fig. 3: cumulative numbers of the susceptibility of 67 onychomycosis-causing yeasts to propolis extract (by flavonoids content, $\mathrm{mg} / \mathrm{ml}$ ), expressed for each observed minimum fungicide concentration.

\section{TABLE II}

Variation interval of the minimum inhibitory concentrations (MIC) of propolis extract against $56^{a}$ different isolated yeasts and their $\mathrm{MIC}_{50}$ and $\mathrm{MIC}_{90}$ values

\begin{tabular}{lrccc}
\hline & & MIC range & $\mathrm{MIC}_{50}$ & $\mathrm{MIC}_{90}$ \\
\cline { 3 - 5 } Microorganism & $\mathrm{N}$ & \multicolumn{3}{c}{$\times 10^{-2} \mathrm{mg} / \mathrm{ml}$} \\
\hline Candida albicans & 8 & $1.25-5.00$ & 2.50 & 2.50 \\
C. parapsilosis & 23 & $0.63-5.00$ & 1.25 & 2.50 \\
C. tropicalis & 15 & $2.50-5.00$ & 2.50 & 5.00 \\
C. lusitanea & 5 & $0.63-5.00$ & 1.25 & 5.00 \\
Trichosporon sp. & 5 & $0.32-1.25$ & 1.25 & 1.25 \\
\hline
\end{tabular}

$a$ : from the 67 yeasts submitted to the susceptibility test, for 11 samples (two C. kefyr, two C. guilliermondii, two C. glabrata, one C. stellatoidea, one Geotrichum candidum, and three Saccharomyces cerevisiae) the calculation of the $\mathrm{MIC}_{50}$ and $\mathrm{MIC}_{90}$ were not possible due to the lack of the required number of samples for the statistical test. 


\section{DISCUSSION}

Yeasts of the Candida genus were found to be the main causal agent of onychomycosis in this region, which is in agreement with (Brilhante et al. 2005) in Ceará, Brazil. Nowadays there are a great variety of drugs with antifungal properties on the market, which are offered in several pharmaceutical forms for either topical or systemic use.

However, before prescribing a treatment for onychomycosis, it is very important to make a diagnosis by direct research and culture of the etiologic agent (Summerbell et al. 2005).

A great proportion of therapeutic failures for onychomycosis are due to incorrect diagnoses, or to a lack of diagnosis. On the other hand, the need for extended treatment, the high cost of treatment, toxicity, and the limited action of classic drugs are also obstacles that need to be overcome. The identification of 67 samples of yeasts showed that $C$. parapsilosis is the most frequent species, being responsible for $35 \%$ of the cases, followed by $C$. tropicalis (23\%) and C. albicans (13\%) (Fig. 1).

These results are in agreement with several publications that also mention the significant increase of non- $C$. albicans species. Torres-Rodrígues (1996) reported that C. parapsilosis has been the most frequently isolated yeast from onychomycosis lesions.

C. albicans has been the yeast of greatest interest in onychomycosis (Brilhante et al. 2005). However in this study C. albicans accounted for only $13 \%$ of the yeasts isolated and identified from nail lesions. The emergence of non-albicans species may represent selection of less susceptible species by classical antifungal agents. This reinforces the importance of laboratory confirmation, in relation to etiology, to aid subsequent treatment, which has been recommended by other authors (Madrenys-Brunet et al. 1996). The occurrence of yeasts resistant to one or more antifungals, which has increased, could be the consequence of the misinformed selection of treatments, or of the appearance of new, more resistant species such as C. lusitanea and C. glabrata (Calvo et al. 1996). Thus the empiric therapeutics that is centered on the $C$. albicans species does not seem to be correct. This concern can already be noticed in committees responsible for the standardization of these tests.

The treatment of onychomycosis is still complicated and not very effective, demanding continuous development of new antifungal medications, reformulation of the ones that already exist, and improvement of the treatment techniques. Under these circumstances, propolis, a mixture of substances of complex composition but without toxicity, has been recommended as a monotherapy or in association with other pharmaceutical products, having demonstrated proven antimicrobial activity (Burdock 1998, Castaldo \& Capasso 2002).

The chemical composition of the propolis extract is still being studied because of its natural variations, so every evaluative study of its biological properties should be followed by some quality parameters, such as $\mathrm{pH}$ value, density, content of active substances and/or markers, and content of dry residue. It can be observed in Table I that the extract in this study showed a total flavonoids con- tent of around $0.92 \%(\mathrm{w} / \mathrm{w})$ and a $\mathrm{pH}$ of 5.62. By knowing the $\mathrm{pH}$, it will be possible to evaluate the degree of aggression the extract will show on the tegumentary tissue.

In the present experiment, different concentrations of the propolis extract were arranged against 67 yeasts from onychomycosis patients and C. parapsilosis (ATCC) to obtain the MIC and MFC of the extract. It was verified that a concentration of $5 \times 10^{-2} \mathrm{mg} / \mathrm{ml}$ of flavonoids was sufficient to completely inhibit the yeasts tested (Fig. 2) and that propolis showed strong in vitro fungistatic activity. The NCCLS document M-27A for antifungal susceptibility tests against yeasts recommends that $C$. parapsilosis should be used as a standard yeast. This species was used as a control in this experiment, maintaining a position in the middle of the range for susceptibility and showing reproducible results.

Propolis extract containing a concentration of $20 \times$ $10^{-2} \mathrm{mg} / \mathrm{ml}$ of flavonoids was sufficient to cause the cellular death of the 67 yeasts (Fig. 3). This result confirms that the activity of propolis not only inhibits growth, but also is highly effective in its fungicidal capacity, and confirms the action and efficiency of propolis as an antimicrobial agent in accord with previous literature (Burdock 1998, Castaldo \& Capasso 2002).

The fungistatic activity can be seen in more detail in the results of Table II. An interval of MIC variation from 0.32 to $5 \times 10^{-2} \mathrm{mg} / \mathrm{ml}$ of flavonoids can be observed, with the following results: for $50 \%$ inhibition, $1.25 \times 10^{-2} \mathrm{mg} / \mathrm{ml}$ of flavonoids were necessary against Trichosporon sp., C. lusitanea, and C. parapsilosis, and $2.5 \times 10^{-2} \mathrm{mg} / \mathrm{ml}$ against $C$. albicans and $C$. tropicalis. For $90 \%$ inhibition of these species, $1.25 \times 10^{-2} \mathrm{mg} / \mathrm{ml}$ of flavonoids were necessary against Trichosporon sp. $2.5 \times 10^{-2} \mathrm{mg} / \mathrm{ml}$ against C. albicans and C. parapsilosis, and $5 \times 10^{-2} \mathrm{mg} / \mathrm{ml}$ against C. lusitanea and C. tropicalis.

Therefore, the species $C$. tropicalis and C. lusitanea required the largest concentrations of propolis to be inhibited $\left(\mathrm{MIC}_{90}\right)$, while the five samples of Trichosporon sp. were all susceptible to the lowest MIC. One of them, $T$. ovoides, was sensitive to the concentration of $0.32 \times 10^{-2}$ $\mathrm{mg} / \mathrm{ml}$ of flavonoids, but this yeast is not a common onychomycosis agent. C. albicans and C. parapsilosis, which are two of the most frequent agents, were located in an intermediate position in the spectrum of sensitivity.

In Table III, a larger interval between the minimum and maximum concentrations necessary for fungicidal activity ( 0.63 to $20 \times 10^{-2} \mathrm{mg} / \mathrm{ml}$ of flavonoids) was observed. This shows that there are differences between the isolates however, confirm that a small increase in propolis concentration enables the fungicidal action of the extract for all then yeasts tested.

In conclusion, the propolis extract showed excellent performance regarding in vitro tests against yeasts identified as onychomycosis agents. This activity is not only fungistatic but also fungicidal, even in small concentrations. Trichosporon sp. were the most susceptible yeasts and $C$. tropicalis the most resistant. The results reinforce the importance and the potential of propolis extract as a treatment for onychomycosis. 


\section{REFERENCES}

Araújo AJG, Bastos OMP, Souza MAJ, Oliveira JC 2003. Onychomycosis caused by emergent fungi: clinical analysis, diagnosis and revision. An Bras Dermatol 78: 445-455.

Baran R, Kaoukhov A 2005. Topical antifungal drugs for the treatment of onychomycosis: an overview of current strategies for monotherapy and combination therapy. $J$ Eur Acad Dermatol Venereol 19: 21-29.

Baran R, Gupta AK, Pierard GE 2005 Pharmacotherapy of onychomycosis. Expert Opin Pharmacother 6: 609-624.

Brilhante RSN, Cordeiro RA, Medrano DJA, Rocha MFG, Monteiro AJ, Cavalcante CSP, Meireles, TEF, Sidrim JJC 2005. Onychomycosis in Ceará (Northeast Brazil): epidemiological and laboratory aspects. Mem Inst Oswaldo Cruz 100: 131-135.

Burdock GA 1998. Review of the biological properties and toxicity of bee propolis. Food Chem Toxicol: 347-363.

Calvo MCR, Tomás JG, Ruesca RB 1996. Valoración in vitro de la sensibilidad a los antifúngicos. Rev Iberoam Micol 13: 60-63.

Castaldo S, Capasso F 2002. Propolis, an old remedy used in modern medicine Fitoterapia 73: s1-s6.

Chi CC, Wang SH, Chou MC 2005. The causative pathogens of onychomycosis in southern Taiwan. Mycoses 48: 413-420.

Cushnie TPT, Lamb AJ 2005. Antimicrobial activity of flavonoids. Int J Antimicrobial Agents 26:343-356.

De Castro SL 2001. Propolis: biological and pharmacological activities. Arbs Amn Rev Biomed Sci 3: 49-83.

Dorko E, Jautova J, Tkacikova L, Wantrubova A 2002. The frequency of Candida species in onychomycosis. Folia Microbiol 47: 727-731.

Effendy I, Lecha M, Feuilhade de Chauvin M, Di Chiacchio N, Baran R 2005. European Onychomycosis Observatory. Epidemiology and clinical classification of onychomycosis. J Eur Acad Dermatol Venereol 19: 8-12.

Ellabib MS, Agaj M, Khalifa Z, Kavanagh K 2002. Yeasts of the genus Candida are the dominant cause of onychomycosis in Libyan women but not men: results of a 2-year surveillance study. Br J Dermatol 146: 1038-1041.

Farmacopéia Brasileira 1988. 4. ed., Atheneu, São Paulo, p. 1.3.1.

Fouilloux B 2003. Onychomycosis and quality of life. Ann Dermatol Venereol 130: 1275-1278.

Franco SL, Bueno JHF 1999. Otimização de processo extrativo de própolis. Infarma 11: 48-51.

Garg A, Venkatesh V, Singh M, Pathak KP, Kaushal GP, Agrawal SK 2004. Onychomycosis in central India: a clinicoetiologic correlation. Int J Dermatol 43: 498-502.

Gupta AK, Ryder JE, Johnson AM 2004a. Cumulative metaanalysis of systemic antifungal agents for the treatment of onychomycosis. Br J Dermatol 150: 537-544.

Gupta AK, Ryder JE, Summerbell RC 2004b. Onychomycosis: classification and diagnosis. J Drugs Dermatol 3: 51-56.

Ilkit M 2005. Onychomycosis in Adana, Turkey: a 5-year study. Int J Dermatol 44: 851-854.

Ioannidou DJ, Maraki S, Krasagakis SK, Tosca A, Tselentis Y 2006. The epidemiology of onychomycoses in Crete, Greece, between 1992 and 2001. J Eur Acad Dermatol Venereol 20: 170-174.

Lecha M, Effendy I, Feuilhade de Chauvin M, Di Chiacchio N, Baran R 2005. Taskforce on Onychomycosis Education. Treatment options-development of consensus guidelines. J Eur Acad Dermatol Venereol 19: 25-33.

Madrenys-Brunet N, Torres-Rodrígue JM, Urea-Arbeláez A 1996. Estudo epidemiológico de las micosis ungueales en Barcelona. Rev Iberoam Micol 13: 14-17.

Mello JCP, Petereit F and Nahrstedt A 1996. Prorobinetinidins from Sthryphnodendron adstringens. Phytochemistry 42: 857-862.

Mujica MT, Finquelievich JL, Jewtuchowicz V, Iovannitti CA 2004. Prevalence of Candida albicans and Candida nonalbicans in clinical samples during 1999-2001. Rev Argent Microbiol 36: 107-112.

NCCLS-National Committee for Clinical Laboratory Standards 1997. Reference method for broth dilution antifungal susceptibility testing for yeasts. Approved standard M27-A, Wayne, PA.

Roberts DT, Taylor WD, Boyle J 2003. Guidelines for treatment of onychomycosis. Br J Dermatol 148: 402-410.

Romano C, Gianni C, Difonzo EM 2005. Retrospective study of onychomycosis in Italy: 1985-2000. Mycoses 48: 42-44.

Sommez S, Kirilmaz L, Yucesoy M, Yücel B, Ylmaz B 2005. The effect of bee propolis on oral pathogens and human gingival fibroblast. J Ethnopharmacol 102:371-376

Summerbell RC, Cooper E, Bunn U, Jamieson F, Gupta Ak 2005. Onychomycosis: a critical study of techniques and criteria for confirming the etiologic significance of nondermatophytes. Med Mycol 43: 39-59.

Torres-Rodrígues JM 1996. Nuevos hongos patogenos oportunistas emergentes. Rev Iberoam Micol 13: 30-33. 